\title{
The relationship between severity of liver steatosis and metabolic parameters in a sample of Iranian adults
}

\author{
Helda Tutunchi ${ }^{1,2}$, Maryam Saghafi-Asl ${ }^{2}$, Mohammad Asghari-Jafarabadi ${ }^{3}$ and Alireza Ostadrahimi ${ }^{2 *}$
}

\begin{abstract}
Objectives: This study aimed to examine the relationship between severity of liver steatosis and metabolic parameters in a sample of Iranian adults. In this cross-sectional study, a total of 95 subjects aged $>20$ years newly diagnosed with NAFLD were recruited. NAFLD was diagnosed using ultrasonography by a single expert radiologist in a fasting state.

Results: The mean age of the patients was 49.27 (SD 9.7) years, with $53.68 \%$ males and $46.32 \%$ females. Most patients had grade I NAFLD (72.63\%), 25.26\% were grade II, and $2.11 \%$ were grade III on ultrasonography. With increasing severity of liver steatosis, there were statistically significant increases in mean body mass index $(P=0.001)$, serum triglycerides $(P=0.026)$, alanine aminotransferase $(P<0.001)$, aspartate aminotransferase $(P<0.001)$, and fasting blood sugar $(P=0.041)$, and there was a statistically significant decrease in mean serum high-density lipoprotein cholesterol $(P=0.011)$. However, no association was found between severity of liver steatosis and serum total cholesterol $(P=0.271)$, low-density lipoprotein cholesterol $(P=0.341)$, and alkaline phosphatase $(P=0.234)$. In conclusion, the severity of ultrasonographic liver steatosis was significantly associated with abnormal metabolic parameters.
\end{abstract}

Keywords: Body mass index, Metabolic parameters, NAFLD, Obesity, Ultrasonography

\section{Introduction}

Non-alcoholic fatty liver disease (NAFLD) is one of the major causes of chronic liver disease worldwide and is caused by triglyceride (TG) accumulation in the liver cells of more than $5 \%$ of liver weight [1-3]. NAFLD is strongly linked to the increased prevalence of obesity, diabetes mellitus, hypertension, and hyperlipidemia [4, 5]. The disease encompasses a broad clinical spectrum of liver disorders ranging from simple steatosis to nonalcoholic steatohepatitis (NASH), fibrosis, cirrhosis, and in some cases hepatocellular carcinoma (HCC) [6]. Although liver biopsy is the gold standard method for

\footnotetext{
*Correspondence: ostadrahimi@tbzmed.ac.ir

${ }^{2}$ Nutrition Research Center, Department of Clinical Nutrition, School

of Nutrition \& Food Sciences, Tabriz University of Medical Sciences,

Tabriz 5166614711, Iran

Full list of author information is available at the end of the article
}

the diagnosis of NAFLD, ultrasonography is more widely used due to increased health risks and high expenditures related to liver biopsies [4]. Therefore, NAFLD prevalence differs according to the method used for diagnosing and staging NAFLD and study population. Overall, the worldwide prevalence of NAFLD has been estimated to be $20-30 \%[6,7]$. However, in obese subjects, patients with type 2 diabetes mellitus, and those with metabolic syndrome, the estimated prevalence of NAFLD is much higher, ranging from 43 to $92 \%$ [8]. The prevalence of NAFLD in Asian countries has recently increased with increasing obesity, diabetes and metabolic syndrome in this region [9]. Today, NAFLD is considered as a main chronic liver disease in Asia [10]. A number of studies found that higher body mass index (BMI) was associated with an increased risk of NAFLD [3, 11-13]. Moreover, abnormal lipid metabolism or dyslipidemia is one of the

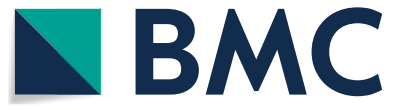

(c) The Author(s) 2020. This article is licensed under a Creative Commons Attribution 4.0 International License, which permits use, sharing, adaptation, distribution and reproduction in any medium or format, as long as you give appropriate credit to the original author(s) and the source, provide a link to the Creative Commons licence, and indicate if changes were made. The images or other third party material in this article are included in the article's Creative Commons licence, unless indicated otherwise in a credit line to the material. If material is not included in the article's Creative Commons licence and your intended use is not permitted by statutory regulation or exceeds the permitted use, you will need to obtain permission directly from the copyright holder. To view a copy of this licence, visit http://creativeco mmons.org/licenses/by/4.0/. The Creative Commons Public Domain Dedication waiver (http://creativecommons.org/publicdomain/ zero/1.0/) applies to the data made available in this article, unless otherwise stated in a credit line to the data. 
common risk factors for NAFLD and is related to cardiovascular mortality, which is the most common cause of death in these patients [14-17]. Although the pathophysiology of dyslipidemia in patients with NAFLD is not fully understood, it is likely associated with hepatic overproduction of the very low-density lipoprotein particles and dysregulated clearance of different lipoproteins from the circulation $[18,19]$. There are few studies investigating the relation of severity of fatty liver with metabolic disorders among Iranian population. Accordingly, this study aimed to examine the relationship between severity of liver steatosis diagnosed by ultrasound and metabolic parameters in a sample of Iranian adults.

\section{Main text}

\section{Materials and methods}

Patients

This cross-sectional study was conducted on a sample of Iranian adults referred to the gastrointestinal clinic at Imam Reza Hospital in Tabriz, Iran, from January to December 2019. The present study included 95 patients who were newly diagnosed with NAFLD. Inclusion criteria included subjects aged more than 20 years old and those with ultrasound-diagnosed NAFLD. Exclusion criteria included individuals with a history of kidney diseases, cardiovascular diseases, hypertension, diabetes, thyroid disorders, gastrointestinal disorders, those diagnosed with some pathological conditions affecting the liver such as viral hepatitis and acute or chronic liver failure, Wilson's disease and hemochromatosis, pregnancy or breast-feeding, a history of significant alcohol intake, the use of any medication that affects lipid or glucose metabolism, adhering to a specific diet during past 3 months, and any lifestyle changes. Informed consent form was obtained from all participants before enrollment in the study. The study protocol was approved by the Ethics Committee of Tabriz University of Medical Sciences, Tabriz, Iran (ethics code; IR.TBZMED. REC.1397.694). This research is complied with the standards of the Declaration of Helsinki and current ethical guidelines.

\section{Liver ultrasonography}

The diagnosis of NAFLD was performed by a radiologist who was blinded to any relevant clinical information, based on ultrasonography (SonoAce X4 ultrasound system, South Korea) in a fasting state. A positive NAFLD diagnosis was attributed when ultrasound examination disclosed hepatic steatosis at any stage and in the absence of excessive consumption of alcoholic beverages (i.e., less than $20 \mathrm{~g} /$ day for women and less than $30 \mathrm{~g} /$ day for men). The following sonographic features of NAFLD were as follows: (1) normal echogenicity; (2) mild, slightly diffuse increase in bright homogenous echoes in the parenchyma, with normal visualization of the of the diaphragm and the hepatic and portal vein borders, and normal hepatorenal contrast if echogenic; (3) moderate, diffuse increase in bright echoes in the liver parenchyma, with slightly impaired visualization of the peripheral portal and hepatic vein borders; and (4) severe, marked increase in bright echoes at a shallow depth, with deep attenuation and impaired visualization of the diaphragm and marked vascular blurring.

\section{Measurements}

Body weights and heights were measured using a digital scale and stadiometer (Seca, Germany). BMI was calculated by dividing weight by squared height $\left(\mathrm{kg} / \mathrm{m}^{2}\right)$. To determine the lipid profile parameters, blood samples $(5 \mathrm{ml})$ were obtained following a 12 -h overnight fast. After centrifugation at $3000 \mathrm{rpm}$ for $5 \mathrm{~min}$, serum levels of TG, total cholesterol (TC), low-density lipoprotein cholesterol (LDL-C), high-density lipoprotein cholesterol (HDL-C), fasting blood sugar (FBS), alanine aminotransferase (ALT), aspartate aminotransferase (AST), and alkaline phosphatase (ALP) were measured by the enzymatic colorimetric method using commercial kits (Pars Azmoon Co., Tehran, Iran).

\section{Statistical analysis}

Statistical analysis of all data was performed using IBM SPSS Statistics software (version 23). To examine the normal distribution of variables, Kolmogorov-Smirnov tests and histograms were applied. In the present study, all variables were normally distributed. Data were presented as mean and standard deviation (SD) for continuous data and frequency (percentage) for categorical variables. To assess the correlation between severity of liver steatosis and metabolic parameters, Pearson's correlation coefficient ( $r$ ) was used. All statistical tests were two-sided, and P-values less than 0.05 were considered statistically significant.

\section{Results}

Table 1 shows the characteristics of the study participants. The mean age of the patients was 49.27 (SD 9.7) years, with $53.68 \%$ males and $46.32 \%$ females. As shown in Table 2, most patients had grade I NAFLD (72.63\%), $25.26 \%$ were grade II, and $2.11 \%$ were grade III on ultrasonography. The majority of the patients were in the age group of 50-59 (41.05\%). Moreover, NAFLD was more common in the overweight (56\%) or obese (class I obesity) $(20 \%)$ patients. Only $14.73 \%$ of the participants had normal weight. As presented in Table 3, with increasing severity of liver steatosis, there were statistically significant increases in mean BMI $(r=0.52, \mathrm{P}=0.001)$, serum 
Table 1 Baseline characteristics of the study participants

\begin{tabular}{ll}
\hline Variable & Mean \pm SD or $\mathbf{n}(\%)$ \\
\hline Age (year) & $49.27 \pm 9.7$ \\
Male gender & $51(53.68 \%)$ \\
BMl $\left(\mathrm{kg} / \mathrm{m}^{2}\right)$ & $29.4 \pm 9.7$ \\
TG $(\mathrm{mg} / \mathrm{dl})$ & $166.2 \pm 59.3$ \\
TC $(\mathrm{mg} / \mathrm{dl})$ & $219.6 \pm 74.2$ \\
LDL-C $(\mathrm{mg} / \mathrm{dl})$ & $151.7 \pm 66.1$ \\
HDL-C $(\mathrm{mg} / \mathrm{dl})$ & $54.2 \pm 19.7$ \\
FBS $(\mathrm{mg} / \mathrm{dl})$ & $97 \pm 29.4$ \\
ALT $(\mathrm{U} / \mathrm{l})$ & $37.6 \pm 16.2$ \\
AST $(\mathrm{U} / \mathrm{l})$ & $27.7 \pm 8.6$ \\
ALP $(\mathrm{U} / \mathrm{l})$ & $188.6 \pm 51.5$ \\
\hline
\end{tabular}

Data presented as the mean \pm standard deviation for quantitative variable and number (\%) for qualitative variables

$B M I$ body mass index, TG triglyceride, $T C$ total cholesterol, $L D L-C$ low-density lipoprotein cholesterol, $H D L-C$ high-density lipoprotein cholesterol, FBS fasting blood sugar, ALT alanine aminotransferase, AST aspartate aminotransferase, ALP alkaline phosphatase

Table 2 Degree of hepatic steatosis in different age groups

\begin{tabular}{llll}
\hline Age group (years) & Grade I-mild & $\begin{array}{l}\text { Grade II- } \\
\text { moderate }\end{array}$ & $\begin{array}{l}\text { Grade } \\
\text { III- } \\
\text { severe }\end{array}$ \\
\hline $20-29$ & 3 & 0 & 0 \\
$30-39$ & 5 & 1 & 0 \\
$40-49$ & 19 & 8 & 1 \\
$50-59$ & 28 & 11 & 1 \\
$\geq 60$ & 14 & 4 & 0 \\
Total & 69 & 24 & 2 \\
Percentage & 72.63 & 25.26 & 2.11 \\
\hline
\end{tabular}

TG $(\mathrm{r}=0.47, \mathrm{P}=0.026)$, ALT $(\mathrm{r}=0.61, \mathrm{P}<0.001)$, AST $(\mathrm{r}=0.52, \mathrm{P}<0.001)$, and FBS $(\mathrm{r}=0.28, \mathrm{P}=0.041)$, and there was a statistically significant decrease in mean HDL-C $(\mathrm{r}=0.38, \mathrm{P}=0.011)$. However, no correlation was found between severity of liver steatosis and serum TC $(\mathrm{r}=0.14, \mathrm{P}=0.271)$, LDL-C $(\mathrm{r}=0.22, \mathrm{P}=0.341)$, and ALP $(\mathrm{r}=0.31, \mathrm{P}=0.234)$.

\section{Discussion}

To the best of our knowledge, this is the first study that investigated the relationship between severity of liver steatosis diagnosed by ultrasound and metabolic parameters in Iranian adults. Our findings demonstrated that the majority of the patients had grade I NAFLD and were overweight or obese. An increasing body of evidence indicates that $\mathrm{BMI}$ is an independent risk factor for NAFLD [12, 13, 20, 21]. Results from a meta-analysis of 21 cohort studies demonstrated that subjects with elevated BMI had a 3.5-fold increased risk for NAFLD, and there was an obvious dose-dependent relationship between BMI and NAFLD risk [20]. In line with our results, study performed by Cuenza et al. [22] and Kim et al. [17] showed that there was statistically significant increase in mean BMI with increasing severity of NAFLD. Similarly, in the PERSIAN Guilan Cohort study (PGCS) located in the north of Iran, a significant positive relationship between BMI and risk of NAFLD was reported [11].

In the present study, severity of liver steatosis was significantly associated with serum TG, HDL-C, ALT, AST, and FBS. However, no association was found between severity of NAFLD and serum TC, LDL-C, and ALP. Similarly, a number of studies have shown

Table 3 Relationship between severity of liver steatosis and metabolic parameters

\begin{tabular}{|c|c|c|c|c|c|c|c|c|}
\hline \multirow[t]{2}{*}{ Parameters } & \multicolumn{2}{|c|}{ Grade I } & \multicolumn{2}{|c|}{ Grade II } & \multicolumn{2}{|c|}{ Grade III } & \multirow[t]{2}{*}{$P$ value } & \multirow[t]{2}{*}{$r$} \\
\hline & Mean & SD & Mean & SD & Mean & SD & & \\
\hline Age & 51 & 11.7 & 49 & 9.7 & 44 & 11.4 & 0.651 & 0.11 \\
\hline BMI $\left(\mathrm{kg} / \mathrm{m}^{2}\right)$ & 28.4 & 5.1 & 29.6 & 7.3 & 32.7 & 8.4 & 0.001 & 0.52 \\
\hline TG (mg/dl) & 151.7 & 61.3 & 167.4 & 46.8 & 183.7 & 52.9 & 0.026 & 0.47 \\
\hline TC (mg/dl) & 211.9 & 71.8 & 204.7 & 51.8 & 208.7 & 61.5 & 0.27 & 0.14 \\
\hline LDL-CT(mg/dl) & 149.4 & 54.2 & 139.7 & $\lceil 33.9$ & $\eta 141.1$ & 55.9 & 0.341 & 0.22 \\
\hline $\mathrm{HDL}-\mathrm{C}(\mathrm{mg} / \mathrm{dl})$ & 58.7 & 24.4 & $\uparrow 51.1$ & $\uparrow 16.6$ & 42.7 & 18.9 & 0.011 & 0.38 \\
\hline FBS (mg/dl) & 103.4 & 44.1 & 109.7 & 42.9 & 116.8 & 38.7 & 0.041 & 0.28 \\
\hline $\operatorname{ALT}(\mathrm{U} / \mathrm{I})$ & 32.9 & $\uparrow 16.8$ & 38.8 & 15.2 & 54.9 & 19.9 & $<0.001$ & 0.61 \\
\hline AST (U/I) & 23.6 & 8.1 & 27.5 & 6.4 & 34.1 & 11.7 & $<0.001$ & 0.52 \\
\hline ALP (U/I) & 177.9 & 54.2 & 181.3 & 60.1 & 169.6 & 71.7 & 0.234 & 0.31 \\
\hline
\end{tabular}

Italic values indicate significance of $P$ value $(P<0.05)$

$B M I$ body mass index, $T G$ triglyceride, $T C$ total cholesterol, $L D L-C$ low-density lipoprotein cholesterol, $H D L$ - $C$ high-density lipoprotein cholesterol, $F B S$ fasting blood sugar, ALT alanine aminotransferase, AST aspartate aminotransferase, ALP alkaline phosphatase

P-values are based on Pearson's correlation coefficient test 
a positive association between abnormal metabolic parameters and risk of NAFLD [22-25]. In line with the current study, study performed by Cuenza et al. [22] among Filipino wellness patients showed that increasing grades of NAFLD was significantly associated with high serum levels of TG, ALT, AST and FBS [23]. Moreover, significant correlation was found between severity of hepatic steatosis and increased serum levels of TC, TG, and LDL-C and decreased levels of HDL-C in the patients with NAFLD in India [24]. Furthermore, study performed by Khanal et al. [23] in adult Nepalese population demonstrated that grades of NAFLD were associated with increased serum levels of cholesterol, LDL-C, and BMI. However, no significant correlation was found between severity of NAFLD and serum levels of TG and HDL-C in the same study. In study performed by Kim et al. [17] among Korean men and women, there were statistically significant progressive increases in mean BMI, serum TC and TG, and significant decrease in mean HDL-C with increasing severity of hepatic steatosis, which support the findings of the present study. Overall, the results of this study indicate that the severity of ultrasonographic liver steatosis was significantly associated with abnormal metabolic parameters in Iranian adults.

\section{Limitations}

The most important strength of the current study was that this study was conducted in patients newly diagnosed with NAFLD, receiving no treatment. The principal limitation of this study was the study design. Because of the cross-sectional nature of the study, one cannot infer causality. Therefore, our findings need to be confirmed in future prospective studies with larger sample sizes.

\begin{abstract}
Abbreviations
ALP: Alkaline phosphatase; ALT: Alanine aminotransferase; AST: Aspartate aminotransferase; BMI: Body mass index; FBS: Fasting blood sugar; HCC: Hepatocellular carcinoma; HDL-C: High-density lipoprotein cholesterol; LDL-C: Low-density lipoprotein cholesterol; NAFLD: Non-alcoholic fatty liver disease; TC: Total cholesterol; TG: Triglyceride.
\end{abstract}

\section{Acknowledgements}

We sincerely thank the patients who participated in the present study.

\begin{abstract}
Authors' contributions
HT, MSA, and AO designed research and contributed to the conception of the project, development of overall research plan, and study oversight. HT contributed to data collection and was the author of the research. MAJ was the statistic counsellor. All approved the final version of this manuscript. All authors read and approved the final manuscript.
\end{abstract}

\section{Funding}

This research was funded by the Nutrition Research Center of Tabriz University of Medical Sciences and Iran National Science Foundation (INSF), Grant
Number: 694 . The funders had no role in study design, data collection and analysis, decision to publish, or preparation of the manuscript.

\section{Availability of data and materials}

The datasets used and/or analyzed during the current study are available from the corresponding author on reasonable request.

\section{Ethics approval and consent to participate}

All procedures performed in this study were in accordance with the ethical standards of the Ethics Committee of Tabriz University of Medical Science. (Registration number: IR.TBZMED.REC.1397.694). Informed written consent was obtained from all participants.

\section{Consent to publish}

Not applicable.

\section{Competing interests}

The authors declare that they have no competing interests.

\begin{abstract}
Author details
${ }^{1}$ Nutrition Research Center, Student Research Committee, School of Nutrition \& Food Sciences, Tabriz University of Medical Sciences, Tabriz, Iran. ${ }^{2}$ Nutrition Research Center, Department of Clinical Nutrition, School of Nutrition \& Food Sciences, Tabriz University of Medical Sciences, Tabriz 5166614711, Iran. ${ }^{3}$ Road Traffic Injury Research Center, School of Health, Tabriz University of Medical Sciences, Tabriz, Iran.
\end{abstract}

Received: 10 March 2020 Accepted: 6 April 2020

Published online: 16 April 2020

\section{References}

1. Younossi ZM, Marchesini G, Pinto-Cortez H, Petta S. Epidemiology of nonalcoholic fatty liver disease and nonalcoholic steatohepatitis: implications for liver transplantation. Transplantation. 2019;103(1):22-7.

2. Younossi ZM. Non-alcoholic fatty liver disease-a global public health perspective. J Hepatol. 2019;70(3):531-44.

3. Tutunchi H, Ostadrahimi A, Saghafi-AsI M. The effects of diets enriched in monounsaturated oleic acid on the management and prevention of obesity: a systematic review of human intervention studies. Adv Nutr. 2020. https://doi.org/10.1093/advances/nmaa013 (ahead of print)

4. Younossi ZM, Golabi P, de Avila L, Paik JM, Srishord M, Fukui N, et al. The global epidemiology of NAFLD and NASH in patients with type 2 diabetes: a systematic review and meta-analysis. J Hepatol. 2019;71(4):793-801.

5. Tutunchi H, Ostadrahim A, Saghafi-Asl M, Hosseinzadeh-Attar MJ, Shakeri A, Jafari-Asgharabadi M, et al. Oleoylethanolamide supplementation in obese patients newly diagnosed with non-alcoholic fatty liver disease: effects on metabolic parameters, anthropometric indices, and expression of PPAR-a, UCP1, and UCP2 genes. Pharmacol Res. 2020. https://doi. org/10.1016/j.phrs.2020.104770 (ahead of print).

6. Tutunchi H, Ostadrahimi A, Saghafi-Asl M, Maleki V. The effects of oleoylethanolamide, an endogenous PPAR-alpha agonist, on risk factors for NAFLD: a systematic review. Obes Rev. 2019;20(7):1057-69.

7. Tutunchi H, Saghafi-Asl M, Ostadrahimi A. A systematic review of the effects of oleoylethanolamide, a high affinity endogenous ligand of PPAR-alpha, on the management and prevention of obesity. Clin Exp Pharmacol Physiol. 2020;47(4):543-52.

8. Perdomo CM, Frühbeck G, Escalada J. Impact of nutritional changes on nonalcoholic fatty liver disease. Nutrients. 2019;11(3):677.

9. Fan JG, Kim SU, Wong VW. New trends on obesity and NAFLD in Asia. J Hepatol. 2017;67(4):862-73.

10. Ashtari S, Pourhoseingholi MA, Zali MR. Non-alcohol fatty liver disease in Asia: prevention and planning. World J Hepatol. 2015;7(13):1788-96.

11. Mansour-Ghanaei R, Mansour-Ghanaei F, Naghipour M, Joukar F, AtrkarRoushan Z, Tabatabaii M, et al. The role of anthropometric indices in the prediction of non-alcoholic fatty liver disease in the PERSIAN Guilan Cohort study (PGCS). J Med Life. 2018;11(3):194-202.

12. Dastgiri S, Ostadrahimi AR, Tutunchi H, Mahboob S. Validity of a short questionnaire (six-items) for food insecurity surveillance in Iran. In: 2nd North American congress of epidemiology, vol. 163, no. 11. 2006. p. S47. 
13. Fan R, Wang J, Du J. Association between body mass index and fatty liver risk: a dose-response analysis. Sci Rep. 2018;8(1):15273.

14. Hoseinikhorrami S, Dastgiri S, Bakhtari F. Epidemiology of food insecurity in the north west of Iran. Res J Biol Sci. 2007;2(4):472-5.

15. Katsiki N, Mikhailidis DP, Mantzoros CS. Non-alcoholic fatty liver disease and dyslipidemia: an update. Metabolism. 2016;65(8):1109-23.

16. Tutunchi H, Ostadrahimi A, Hosseinzadeh-Attar MJ, Miryan M, Mobasseri M, Ebrahimi-Mameghani M. A systematic review of the association of neuregulin 4, a brown fat-enriched secreted factor, with obesity and related metabolic disturbances. Obes Rev. 2020;21(2):e12952.

17. Kim HC, Choi SH, Shin HW, Cheong JY, Lee KW, Lee HC, et al. Severity of ultrasonographic liver steatosis and metabolic syndrome in Korean men and women. World J Gastroenterol. 2005;11(34):5314-21.

18. Chatrath $H$, Vuppalanchi $R$, Chalasani N. Dyslipidemia in patients with nonalcoholic fatty liver disease. Semin Liver Dis. 2012;32(1):22-9.

19. Taskinen MR, Adiels M, Westerbacka J, Soderlund S, Kahri J, Lundbom $N$, et al. Dual metabolic defects are required to produce hypertriglyceridemia in obese subjects. Arterioscler Thromb Vasc Biol. 2011;31(9):2144-50.

20. Li L, Liu DW, Yan HY, Wang ZY, Zhao SH, Wang B. Obesity is an independent risk factor for non-alcoholic fatty liver disease: evidence from a metaanalysis of 21 cohort studies. Obes Rev. 2016;17(6):510-9.
21. Tutunchi H, Asghari Jafarabadi M, Hoojeghani S, Tabrizi S, Farrin N, Ostadrahimi A. General and abdominal obesity is related to socioeconomic status and food choices: a cross-sectional study. Nutr Food Sci. 2019;50:61-73.

22. Cuenza LR, Razon TLJ, Dayrit JC. Correlation between severity of ultrasonographic nonalcoholic fatty liver disease and cardiometabolic risk among Filipino wellness patients. J Cardiovasc Thorac Res. 2017;9(2):85-9.

23. Khanal UP, Paudel B, Gurung G, Hu YS, Kuo CW. Correlational study of nonalcoholic fatty liver disease diagnosed by ultrasonography with lipid profile and body mass index in adult nepalese population. J Med Ultrasound. 2019;27(1):19-25.

24. Mahaling DU, Basavaraj MM, Bika AJ. Comparison of lipid profile in different grades of non-alcoholic fatty liver disease diagnosed on ultrasound. Asian Pac J Trop Biomed. 2013;3(11):907-12.

25. Ostadrahimi A, Mahboob S, Tutunchi H, Dastgiri S. Prevalence and intensity of food insecurity (hunger and hidden hunger aspects) in AsadAbadi region of Tabriz. Yafteh. 2006;8(1):75-81.

\section{Publisher's Note}

Springer Nature remains neutral with regard to jurisdictional claims in published maps and institutional affiliations.
Ready to submit your research? Choose BMC and benefit from:

- fast, convenient online submission

- thorough peer review by experienced researchers in your field

- rapid publication on acceptance

- support for research data, including large and complex data types

- gold Open Access which fosters wider collaboration and increased citations

- maximum visibility for your research: over $100 \mathrm{M}$ website views per year

At BMC, research is always in progress.

Learn more biomedcentral.com/submissions 